\title{
Türkiye'de Spor Alanına Özgü Üniversitelerin Önemi
}

\author{
DOI: $10.26466 /$ opus.571605 \\ * \\ Orhan Ahmet Şener * - Osman İmamoğlu** \\ *Dr Öğretim görevlisi, Selçuk Üniversitesi, Spor Bilimleri Fakültesi, Konya / Türkiye \\ E-Posta: orhansener42@hotmail.com \\ ORCID: 0000-0002-3580-4362 \\ Prof. Dr., Ondokuz Mayıs Üniversitesi, Yaşar Doğu Spor Bilimleri Fakültesi, Samsun/ Türkiye \\ E-Posta: osmani55@hotmail.com \\ ORCID: $\underline{0000-0001-6671-6042}$
}

\section{Öz}

Bu çalışmanın amacı, Türkiye'de spor üniversitelerinin kurulmasının önemini açıklamaktır. Literatür taraması yapıldı. Dünyanın değişik ülkelerinde spor üniversiteleri ve spor enstitüleri bulunmaktadır. Bazı üniversitelerde ise güçlü spor fakülteleri, spor yüksekokulları veya diğer fakültelere bağhl sporla ilgili bölümler mevcuttur. Türkiye'de Spor fakülteleri, Spor Yüksekokulları ve başka fakültelere bağh sporla ilgili bölümler bulunmaktadır. Sporla ilgili sıralamalarda üniversiteleri ilk straları alan devletlerin olimpiyatlarda da başarılı olduğu görülmüştür. Yine Global spor indeksine göre başarılı olan ülkeler sporda da başarılı olduğu tespit edilmiştir.Sonuç: Türkiye'de bir veya birkaç Spor alanına özel Üniversitenin acilen kurulmasına ihtiyaç olduğu sonucuna varılmıştır. Türkiye'de Spor Üniversitelerinin kurulması Türkiye'ye sportif, sosyal, ekonomik ve siyasal anlamda başarı ve itibar kazandıracaktır. Söz konusu üniversite veya üniversitelerin spor tesisleri iklimsel özelliklerde dikkate alınarak kurulmasinda fayda vardır. Ankara, İstanbul, İzmir gibi büyük illerde spor üniversitesi kurulması gerekmektedir. Ayrıca kış sporları için Erzurum, Yaz sporları için Antalya ve Mücadele sporları için Karadeniz orta şehri samsunda birer üniversite kurulması önerilebilir.

Anahtar Kelimeler: Türkiye, Üniversite, Spor 


\title{
The Importance of The University in Sports Science's Field
}

\begin{abstract}
The aim of this study is to explain the importance of establishing universities of sports in Turkey. Literature review was performed. There are sports universities and sports institutes in different countries of the world. In some universities, there are sports-related departments, sports schools (College) or other sports related departments. Sports faculties in Turkey, sports schools and sports-related departments linked to other faculties are available. The states that ranked first in the sports related rankings were also successful in the Olympics. The countries which are successful according to the Global sports index have been found to be successful in sports. Conclusion: It was concluded that one or more of sports University in Turkey that there needs to be urgently established. The establishment of the Sports University in Turkey in Turkey sporting, social, economic and political sense will bring success and reputation. It is useful to establish the universities or universities in question by considering the sports facilities in climatic conditions. It need Establishment of Sports University in the major cities such as Ankara, Istanbul and Izmir. In addition, it may be recommended to establish a university for winter sports in Erzurum, Antalya for summer sports and a university in the middle of the Black Sea for Fighting Sports.
\end{abstract}

Keywords: Turkey, University, Sports 


\section{Giriş}

Dünyada Spor veya Beden Eğitimi konusunda direk eğitim veren üniversiteler kurulmuştur. Bu üniversitelerin altısı Çin'de kurulmuştur. Polonya'da ise 4 tane ve Almanya, Litvanya, Japonya, Rusya, İspanya, Letonya ve Tayvan'da birer tane bulunmaktadır. Çin'de kurulan üniversitelerin hepsi 1952- 1958 yılları arasında kurulmuş olması çok dikkat çekicidir. Diğer Spor üniversitelerin kuruluş tarihleri 1919 ve 1996 yılları arasında değişmektedir.

Dünyada değişik ülkelerde sadece ana amacı sporla ilgilenme olan Spor Enstitüleri, Akademileri ve Üniversiteleri bulunmaktadır. Ayrıca bazı ülkelerde de bağımsız Spor Yüksekokulları vardır. Ukrayna'da Ulusal Spor Enstitüsü ve buna bağlı çeşitli Spor Fakülteleri vardır. Avustralya'da Üniversitelere bağlı Fakültelerde Spor Yüksekokulları ve Gençlik Enstitüleri bulunmaktadır. Türkiye'de ise Üniversitelere bağlı spor fakülteleri, Spor Yüksekokulları ve değişik Fakültelere bağlı Beden Eğitimi ve Spor/rekreasyon bölümleri mevcuttur.

Türkiye'de Spor Enstitüsü ve Spor Üniversitesi mevcut değildir. Genel itibari ile Spor Fakülteleri ve Spor Yüksekokullarına bağlı bölümler de spor eğitimi verilmektedir. Mevcut bölümlerin çoğu program adının "Beden Eğitimi ve Spor Öğretmenliği Bölümü", "Antrenörlük Eğitimi Bölümü", "Spor yöneticiliği bölümü" ve "Rekreasyon bölümü" şeklindedir. Oysa dünyadaki özellikle de gelişmiş batı toplumlarındaki yapılanmaya baktığımızda durumun böyle olmadığı görülmektedir. Çünkü spor bilimleri alanı disiplinler arası bir alandır. Bazı ülkelerde Beden Eğitimi ve Spor Üniversiteleri ve bunlara bağlı fakülte, yüksekokul ve enstitüler vardır. Bazı ülkelerde beden Eğitimi ve Spor, Rekreasyon, Gençlik, Fiziksel Aktivite Enstitüleri mevcuttur. Bazılarında ise Beden Eğitimi, Spor, Rekreasyon, Beden Eğitimi ve spor, Spor Terapisi Fakülte ve Yüksekokulları bulunmaktadır (İmamoğlu,2018).

Türkiye'de Spor alanına özel bir enstitü bulunmadığından Yüksek lisans ve doktora programları değişik üniversitelerin değişik enstitülerinde ve değişik anabilim dalları altında yer almaktadır. Bu yapılanmada bazı aksaklıklar oluşmaktadır. Bu çalışmada spor alanında dünyadaki üniversite örneklerini inceleyerek Türkiye' de nasıl bir yapılanma olması gerektiği üzerinde durmaktadır. 


\section{Metot}

Bu çalışmada literatür taraması yapılmıştır. Nicel araştırma yöntemi kullanılmıştır. Ayrıca internet taraması yapılmıştır.

\section{Bulgular ve Tartışma}

Spor bilimleri alanında dünyadaki Üniversiteler: 2017 yılında ilk kez konuya göre QS Dünya Üniversiteleri Sıralaması yapılmıştır. Sporla ilgili konular için dünyanın en iyi 100 üniversitesi sıralanmaktadır. Bu sıralamada, spor (veya egzersiz) bilimi, spor çalışmaları ve hareket bilimi uygun görülmüştür. Bireysel derece içeriğine bağlı olarak, spor psikolojisi ve spor yönetimi de düşünülebilir. QS spor bilimleri alanında sıralamaya giren üniversiteler Akademik itibar, İşverenin itibarı ve yayın başına atıflar ve H-Endeksi durumuna dayanmaktadır. 2018 Yılı için derecelendirmede ise aday üniversiteleri iki kriter üzerinden ele alınmıştır. İlk olarak, aday ya bir spor üniversitesi olmalı ya da sporla ilgili birimlere sahip olmalıdır. İkincisi, spor üniversitesi veya sporla ilgili birimler, son beş yılda belirli bir sayıda Web of Science makalesi (aktif olarak araştırmaya katılan) yayınlamalıdır. Toplamda, 400 spor birliği ile 372 üniversite seçildi ve derecelendirildi. Üniversiteler, Web of Science'da indekslenen makaleler, toplam alıntılar, makale başına alıntılar,\% 25 dergide yayınlanan makaleler ve uluslararası işbirliğine dayalı bildirilerin yüzdesi de dahil olmak üzere çeşitli akademik veya araştırma performans göstergelerine göre sıralanmıştır. 2018 ve 2019 yılları için sıralama kriterleri: Web of Science indeksli makaleler \% 20, Bir kurum tarafından yayınlanan makalelere yapılan atıfların sayısı \%20, Sayfa başına alıntı \%25, En iyi \% 25-e giren dergilerde yayınlanan makaleler\%25 ve Bir kurumun uluslararası ortak yazarlığa sahip yayınlarının yüzdesi\%10.

2017 yılı sıralamasında İngiltere, Avustralya, Kanada ve Amerika Birleşik Devletleri (ABD) Üniversiteleri ilk 10 içerisinde bulunmaktadır (Tablo 1). 2017 yılındaki kriterler dikkate alındığında spor bilimleri alanında dünyanın ilk 100 sıralamasına giren üniversiteler arasında Türk Üniversitesi yer almamaktadır (İmamoğlu,2018). 2018 ve 2019 yıllarındaki sporla ilgili üniversitelerin başarı sıralamasına bakıldığında çok az Üniversitenin ilk 25 içerinde değiştiği görülmektedir (Tablo 2). Yine Amerika 
Birleşik Devletleri, İngiltere, Kanada, Avustralya, Japonya ile Çin ve Japonya ya komşu ülkelerinin üniversiteleri ilk sıralarda yer almıştır. Bu ülkeler spor alanında madalya kazanma anlamında da başarılı olan devletlerdir. Bu ülkeler arasında olmayan ama spor alanında başarılı olan ülkelerde mevcuttur. Örneğin Rusya, Küba ve Arjantin örnek olarak verilebilir.

Tablo 1. 2017 QS Dünya Üniversite Stralamasına dayanarak Dünyadaki sporla ilgili konular için en iyi 10 üniversite

\begin{tabular}{lll}
\hline Sıra & Üniversite adı: ilgili spor enstitü ve fakülteleri & Ülke \\
\hline 1 & $\begin{array}{l}\text { Loughborough Üniversitesi: Spor Egzersiz ve Sağlık } \\
\text { Bilimleri Okulu/ Spor Teknoloji Enstitüsü }\end{array}$ & İngiltere \\
\hline 1 & $\begin{array}{l}\text { Sidney Üniversitesi: Sağlık Bilimleri Fakültesi Egzersiz ve } \\
\text { Spor Bilimi Bölümü }\end{array}$ & Avustralya \\
\hline 3 & $\begin{array}{l}\text { Queensland Üniversitesi: İnsan Hareketi ve Beslenme Bi- } \\
\text { limi Okulu }\end{array}$ & Avustralya \\
\hline 4 & $\begin{array}{l}\text { British Columbia Üniversitesi: Sağlık ve Sosyal Gelişim Fa- } \\
\text { kültesi Sağlık ve Egzersiz Bilimleri Okulu/ Allan Mcgavin }\end{array}$ & \\
& Spor Tıbbi Merkezi/Kinesyoloji okulu \\
\hline 5 & $\begin{array}{l}\text { Birmingham Üniversitesi: Spor Egzersiz ve Rehabilitasyon } \\
\text { Bilimleri okulu }\end{array}$ & İngiltere \\
\hline 6 & $\begin{array}{l}\text { Toronto Üniversitesi: Beden Eğitimi ve Kinesyoloji Fakül- } \\
\text { tesi }\end{array}$ & Kanada \\
\hline 7 & Otago Üniveristesi: Beden Eğitimi okulu & Yeni Zelanda \\
\hline 8 & $\begin{array}{l}\text { Pensilvanya Devlet Üniversitesi: Sağlık ve İnsan Gelişim } \\
\text { Okulu }\end{array}$ & ABD \\
\hline 8 & Florida Üniversitesi: Sağlık ve İnsan Performansı Okulu & ABD \\
\hline 10 & $\begin{array}{l}\text { Alberta Üniversitesi: Beden Eğitimi ve Rekreasyon Fakül- } \\
\text { tesi }\end{array}$ & Kanada \\
\hline
\end{tabular}


Tablo 2. Dünya' da 2018 ve 2019 yılları arası Sporla İlgili Üniversite Sıralaması (En iyi 25 üniversite)

\begin{tabular}{|c|c|c|c|}
\hline Üniversite veya Enstitü adı & 2018 & 2019 & Ülke \\
\hline Loughborough University & 1 & 1 & Birleşik krallık \\
\hline The University of Sydney & 2 & 4 & Avustralya \\
\hline The University of Queensland & 3 & 2 & Avustralya \\
\hline University of British Columbia & 4 & 3 & Kanada \\
\hline University of Birmingham & 5 & 6 & Birleşik krallık \\
\hline University of Toronto & 6 & 5 & Kanada \\
\hline University of Alberta & 7 & 9 & Kanada \\
\hline Pennsylvania State University & 8 & 16 & $\mathrm{ABD}$ \\
\hline Massachusetts Institute of Technology & 9 & 22 & $\mathrm{ABD}$ \\
\hline The Ohio State University & 27 & 8 & $\mathrm{ABD}$ \\
\hline KU Leuven & 30 & 11 & Belçika \\
\hline Seoul National University & 10 & 12 & Güney Kore \\
\hline Deakin University & 30 & 15 & Avustralya \\
\hline The University of Hong Kong & 11 & 16 & Hong Kong \\
\hline University of Otago & 12 & 20 & Yeni Zelanda \\
\hline The University of Exeter & 13 & 12 & Birleşik krallık \\
\hline University of Florida & 14 & 7 & $\mathrm{ABD}$ \\
\hline University of Copenhagen & 15 & 18 & Danimarka \\
\hline University of Bath & 16 & 10 & Birleşik krallık \\
\hline University of Michigan & 17 & 12 & $\mathrm{ABD}$ \\
\hline University of Illinois at Urbana-Champaign & 18 & 35 & $\mathrm{ABD}$ \\
\hline The University of Edinburgh & 19 & 37 & Birleşik krallık \\
\hline Universidade de São Paulo & 20 & 27 & Brezilya \\
\hline McMaster University & 21 & 23 & Kanada \\
\hline The Chinese University of Hong Kong (CUHK) & 21 & 44 & Hong Kong \\
\hline The University of Western Avustralya & 21 & 24 & Avustralya \\
\hline National Taiwan University (NTU) & 24 & 19 & Taland \\
\hline University of Tsukuba & 25 & 49 & Japan \\
\hline $\mathrm{UCL}$ & 39 & 21 & Birleşik Krallık \\
\hline University of Technology Sydney & 33 & 24 & Avustralya \\
\hline
\end{tabular}

\section{Asya'daki en iyi sporla ilgili üniversiteler}

2017 yılı için; Asya üniversiteleri, sporla ilgili konularda ilk 100'e giren 13 üniversite vardı. Güney Kore, Yonsei Üniversitesi ile birlikte 3 üniversite tarafından etkileyici bir şekilde temsil ediliyor. Japonya'nın da 2017 listesinin en üstteki 50 içinde olan 3 temsilcisi var. Bunlar Waseda Üniversitesi19, Tsukuba Üniversitesi 26 ve Kyoto Üniversitesi 33. Sıradadır. Hong Kong ve Singapur'un her ikisi de sporla ilgili konu sıralamasinda birer 
üniversiteye sahip. Hong Kong Üniversitesi 11. ve Hong Kong Çin Üniversitesi 26. sırada yer alırken, Singapur Ulusal Üniversitesi 46. sırada yer alan en yüksek Singapur üniversitesidir. Çin, Malezya ve Tayvan'ın her biri listede birer üniversiteye sahiptir. Bu üç üniversiteden sadece bir tanesi ilk 50' içindedir. Ulusal Tayvan Üniversitesi 15. Sıradadır (İmamoğlu,2018). 2018 ve 2019 yılı için; ilk 50 içerisinde Güney Kore, Hong Kong, Tayvan, Japonya ve Singapur'dan üniversiteler bulunmaktadır (Tablo 3).

Tablo 3. Asya'daki en iyi sporla ilgili üniversitelerin sıralaması (2018 ve 2019 yılları, ilk 50 Üniversite içinde)

\begin{tabular}{llll}
\hline Üniversite & $\mathbf{2 0 1 8}$ & $\mathbf{2 0 1 9}$ & Ülke \\
\hline Seul Ulusal Üniversitesi & 10 & 12 & Güney Kore \\
\hline Hong Kong Üniversitesi & 11 & 16 & Hong Kong \\
\hline Çin Üniversitesi & 21 & 44 & Hong Kong \\
\hline Ulusal Tayvan Üniversitesi & 24 & 19 & Tayvan \\
\hline Tsukuba Üniversitesi & 25 & 49 & Japonya \\
\hline Ulusan Singapur Üniversitesi & 37 & 40 & Singapur \\
\hline Waseda Üniversitesi & 40 & 42 & Japonya \\
\hline Kyoto Üniversitesi & 46 & 34 & Japonya \\
\hline
\end{tabular}

\section{Amerika Kıtasında sporla ilgili en iyi üniversiteler}

2017 yılı için; İlk 10' da Kanada 3 ve ABD 2 üniversite vardı. ABD 22 üniversite ile öne çıkmıştır. Bunların 14'ü ilk 50'dedir.

Tablo 4. Amerika Birleşik Devletleri ve Kanada'da sporla ilgili en iyi üniversiteler sıralaması (2018ve 2019 yıllar), ilk 50 Üniversite içinde

\begin{tabular}{llll}
\hline Üniversite & $\mathbf{2 0 1 8}$ & $\mathbf{2 0 1 9}$ & Ülke \\
\hline Britanya Kolombiyasi Üniversitesi & 4 & 3 & Kanada \\
\hline Toronto Üniversitesi & 6 & 5 & Kanada \\
\hline Alberta Üniversitesi & 7 & 9 & Kanada \\
\hline Pennsylvania Eyalet Üniversitesi & 8 & 16 & Amerika \\
\hline Massachusetts Teknoloji Enstitüsü & 9 & 22 & Amerika \\
\hline Florida Üniversitesi & 14 & 7 & Amerika \\
\hline University of Michigan & 17 & 2 & Amerika \\
\hline University of Illinois & 18 & 35 & Amerika \\
\hline Michigan Master Üniversitesi & 21 & 12 & Kanada \\
\hline McGill Üniversitesi & 26 & 28 & Kanada \\
\hline Ohio Eyalet Üniversitesi & 27 & 8 & Amerika
\end{tabular}




\begin{tabular}{llll}
\hline Massachusetts Amherst Üniversitesi & 29 & 46 & Amerika \\
\hline Michigan Eyalet Üniversitesi & 35 & $51-100$ & Amerika \\
\hline Calgary Üniversitesi & 41 & 30 & Kanada \\
\hline Boston Üniversitesi & 42 & $51-100$ & Amerika \\
\hline Maryland Üniversitesi & 44 & $51-100$ & Amerika \\
\hline Cornell Üniversitesi & 47 & $51-100$ & Amerika \\
\hline Kuzeybatı Üniversitesi & 47 & $51-100$ & Amerika \\
\hline Batı Ontario Üniversitesi & 50 & $51-100$ & Kanada \\
\hline Sao Paulo Üniversitesi & 20 & 27 & Brezilya \\
\hline Üminas Gerais Üniversitesi & $51-100$ & & Brezilya \\
\hline
\end{tabular}

Kanada'nın bu 2017 sıralamasında ilk 10 içinde 3 üniversite vardır.2018 yılı için ilk 50 Üniversiteye bakıldığında ilk 10'da Kanada' dan 3 üniversite ve $A B D^{\prime}$ den bir üniversite ve bir enstitü bulunmaktadır. İlk 50 içerisinde Kanada'dan 7 üniversite varken 43 üniversite veya enstitü ABD'de bulunmaktadır (İmamoğlu,2018). 2018 ve 2019 yılı içinde Yine ABD ve Kanada Üniversiteleri hemen hemen aynı üniversitelerdir. Brezilyadan bir Üniversite ilk 27 içerisinde yer almaktadır.

\section{Afrika Ülkelerinde Üniversiteler}

Tek bir ülkedeki bir Üniversite sıralamaya girmiştir.

Tablo 5. Afrika'daki en iyi sporla ilgili üniversitelerin stralaması

\begin{tabular}{llll}
\hline Üniversite & 2018 & $\mathbf{2 0 1 9}$ & Ülke \\
\hline Cape Town Üniversitesi & 37 & $51-100$ & Güney Afrika \\
\hline
\end{tabular}

\section{Avrupa sporla ilgili en iyi üniversiteler sıralaması}

2017 yılı için; ilk kez spor konulu sıralamada 17 üniversite ile İngiltere, Avrupa'da baskındır. Hollanda, listenin en üst düzeydeki en iyi spor üniversiteleri konumuna sahiptir. Belçika, Danimarka ve Portekiz'in 2017 listesinde iki üniversite vardır. Finlandiya, İrlanda ve Norveç'in hepsinin birer üniversitesi vardı. 2018 ve 2019 yılı için; Hemen hemen aynı üniversiteler yer almaktadır. Sıralamalarına değişiklikler olmuştur. Afrika'dan sadece bir üniversite ilk 50-100 bandında yer almaktadır. 
Tablo 6. Avrupa sporla ilgili en iyi üniversiteler sıralaması (2018 ve 2019 yılları)

\begin{tabular}{llll}
\hline Üniversite & $\mathbf{2 0 1 8}$ & $\mathbf{2 0 1 9}$ & Ülke \\
\hline $\begin{array}{l}\text { Loughborough Üniversitesi/ Spor, Egzersiz } \\
\text { ve Sağllk Bilimleri Fakültesi }\end{array}$ & 1 & 1 & $\begin{array}{l}\text { Birleşik Krallık/ } \\
\text { İngiltere }\end{array}$ \\
\hline $\begin{array}{l}\text { Birmingham Üniversitesi/ Egzersiz ve Reha- } \\
\text { bilitasyon Bilimleri }\end{array}$ & 5 & 6 & Birleşik Krallık \\
\hline Exeter Üniversitesi & 13 & 12 & Birleşik Krallık \\
\hline Kopenhag Üniversitesi & 15 & 18 & Danimarka \\
\hline Bath Üniversitesi & 16 & 10 & Birleşik Krallık \\
\hline Edinburgh Üniversitesi & 19 & 37 & Birleşik Krallık \\
\hline $\begin{array}{l}\text { Leuven Üniversitesi/ Kinesiyoloji ve Rehabi- } \\
\text { litasyon Fakültesi }\end{array}$ & 30 & 11 & Belçika \\
\hline $\begin{array}{l}\text { Ghent Üniversitesi/ Hareket ve Spor Bilimleri } \\
\text { Bölümü }\end{array}$ & 33 & 42 & Belçika \\
\hline UCL Üniversitesi & 39 & 21 & Birleşik krallık \\
\hline $\begin{array}{l}\text { Liverpol John Üniversitesi/ Spor ve Egzersiz } \\
\text { Bilimleri Fakültesi }\end{array}$ & 44 & & Birleşik Krallık \\
\hline Autónoma de Madrid & 49 & $51-100$ & İspanya \\
\hline Brunel Üniversitesi & $51-100$ & & Birleşik Krallık \\
\hline Cardiff Üniversitesi & $51-100$ & & Birleşik Krallık \\
\hline Delft Teknoloji Üniversitesi & $51-100$ & & Hollanda \\
\hline Rotrerdam Erasmus Üniversitesi & $51-100$ & & Hollanda \\
\hline ETH Zürih teknoloji enstitüsü & $51-100$ & & İsviçre \\
\hline Manschester Metropolitan Üniversitesi & $51-100$ & & Birleşik krallık \\
\hline Manchester Üniversitesi & $51-100$ & & Birleşik krallık \\
\hline Nottingham Üniversitesi & $51-100$ & & Birleşik krallık \\
\hline Duplin Tirinty Koleji & $51-100$ & & İrlanda \\
\hline Alma Mater Studiorum Üniversitesi & $51-100$ & & İtalya \\
\hline Barselona Üniversitesi & $51-100$ & & İspanya \\
\hline Albert Ludwig Üniversitesi & $51-100$ & $51-100$ & Almanya \\
\hline & & & \\
\hline & & & \\
\hline
\end{tabular}

\section{Avustralya Üniversiteleri}

Sporla ilgili sıralamada 2017 Yılında daha başarılı oldukları görülmüştür. 2018 ve 2019 yılları için 6 üniversite ilk 50 bandında yer almaktadır. Sydney ve Queesland Üniversiteleri dünyada 2 ve 3.'lük konumların 2018 ve 2019 yıllarında korumuşlardır. Avustralya İngiltere bağlantılı bir ülke olduğu için spor alanında da Üniversiteleri önde olmuş olabileceği düşünülmektedir. 
Tablo 7. Avustralya'daki en iyi sporla ilgili üniversitelerin sıralaması

\begin{tabular}{llll}
\hline Üniversite & $\mathbf{2 0 1 8}$ & $\mathbf{2 0 1 9}$ & Ülke \\
\hline Sidney Üniversitesi & 2 & 3 & Avustralya \\
\hline Queensland Üniversitesi & 3 & 2 & Avustralya \\
\hline Batı Avustralya Üniversitesi & 21 & 24 & Avustralya \\
\hline Deakin Üniversitesi & 30 & 15 & Avustralya \\
\hline Yeni Güney Galler Üniversitesi & 32 & $51-100$ & Avustralya \\
\hline Sydney Teknik Üniversitesi & 33 & 24 & Avustralya \\
\hline
\end{tabular}

Tablo 8. CEOWORLD dergisine göre 2019'da Dünyanın En İyi Spor Bilimleri ve Yönetimi Üniversiteleri (İlk 25 Üniversite)

\begin{tabular}{|c|c|c|c|}
\hline Sira & Üniversite & Ülke & Puan \\
\hline 1 & Güney Carolina Üniversitesi, Spor Yönetimi Fakültesi & Amerika Birleşik Devletleri & 983 \\
\hline 2 & $\begin{array}{l}\text { Loughborough Üniversitesi Spor, Egzersiz ve Sağlık Bilim- } \\
\text { leri Fakültesi }\end{array}$ & Birleşik Krallık & 982 \\
\hline 3 & $\begin{array}{l}\text { Deakin Üniversitesi Egzersiz ve Beslenme Bilimleri Yükse- } \\
\text { kokulu }\end{array}$ & Avustralya & 981 \\
\hline 4 & Norveç Spor Bilimleri Okulu (NIH) & Norveç & 979 \\
\hline 5 & $\begin{array}{l}\text { Queensland Üniversitesi, İnsan Hareketi ve Beslenme Bilim- } \\
\text { leri Fakültesi }\end{array}$ & Avustralya & 970 \\
\hline 6 & $\begin{array}{l}\text { Birmingham Üniversitesi, Spor, Egzersiz ve Rehabilitasyon } \\
\text { Bilimleri Fakültesi }\end{array}$ & Birleşik Krallık & 968 \\
\hline 7 & Illinois Üniversitesi & Amerika Birleşik Devletleri & 967 \\
\hline 8 & $\begin{array}{l}\text { Danimarka Üniversitesi Spor Bilimleri ve Klinik Biyomeka- } \\
\text { nik Anabilim Dalı }\end{array}$ & Danimarka & 966 \\
\hline 9 & York Üniversitesi Kinesiyoloji ve Sağlık Bilimleri Fakültesi & Kanada & 964 \\
\hline 10 & $\begin{array}{l}\text { Liverpool John Moores Üniversitesi Spor ve Egzersiz Bilim- } \\
\text { leri Fakültesi }\end{array}$ & Birleşik Krallık & 955 \\
\hline 11 & Kopenhag Üniversitesi & Danimarka & 953 \\
\hline 12 & Köln Alman Spor Üniversitesi & Almanya & 951 \\
\hline 13 & İngiliz Kolombiya Üniversitesi & Kanada & 943 \\
\hline 14 & Verona Üniversitesi Egzersiz ve Spor Bilimleri Fakültesi & İtalya & 941 \\
\hline 15 & $\begin{array}{l}\text { KU Leuven, Kinesiyoloji ve Rehabilitasyon Bilimleri Fakül- } \\
\text { tesi }\end{array}$ & Belçika & 935 \\
\hline 16 & $\begin{array}{l}\text { Egzersiz ve Sağlık Bilimleri Fakültesi, Edith Cowan Üniver- } \\
\text { sitesi }\end{array}$ & Avustralya & 933 \\
\hline 17 & Ghent Üniversitesi, Hareket ve Spor Bilimleri Bölümü & Belçika & 932 \\
\hline 18 & $\begin{array}{l}\text { Bat1 Avustralya Üniversitesi Spor Bilimleri, Egzersiz ve Sağ- } \\
\text { lık Okulu, }\end{array}$ & Avustralya & 931 \\
\hline 19 & Laval Üniversitesi, Kinesiyoloji Anabilim Dalı & Kanada & 927 \\
\hline 20 & Sao Paulo Üniversitesi, Beden Eğitimi ve Spor Yüksekokulu & Brezilya & 923 \\
\hline 21 & Waterloo Üniversitesi, Kinesiyoloji Anabilim Dalı & Kanada & 916 \\
\hline 22 & Maastricht Üniversitesi, İnsan Hareketi Bilimi Anabilim Dalı & Hollanda & 914 \\
\hline 23 & Groningen Üniversitesi & Hollanda & 910 \\
\hline 24 & Alberta Üniversitesi, Beden Eğitimi ve Rekreasyon Fakültesi & Kanada & 908 \\
\hline 25 & $\begin{array}{l}\text { Vrije Universitesi Amsterdam İnsan Hareketi Bilimleri Bö- } \\
\text { lümü }\end{array}$ & Hollanda & 905 \\
\hline
\end{tabular}

\section{CEOWORLD dergisine göre, Güney Carolina Üniversitesi'ndeki Ağır-} lama, Perakende ve Spor Yönetimi Koleji, 2019 yılında dünyanın en iyi 
Spor Bilimi ve Yönetimi üniversitesi seçilmiştir. Loughborough Üniversitesi Spor, Egzersiz ve Sağlık Bilimleri Fakültesi ve Deakin Üniversitesi Egzersiz ve Beslenme Bilimleri Fakültesi/Yüksekokulu sırasıyla 2. ve 3. s1rada yer aldı. 2019 sıralaması, Norveç Spor Bilimleri Okulu (NIH) İnsan Hareketi ve Beslenme Bilimleri Fakültesi 4. sıraya yerleşti. Queensland Üniversitesi 5. Siraya ve Birmingham Üniversitesi'nde Spor, Egzersiz ve Rehabilitasyon Bilimleri Yüksekokulu 6. Sırayı aldı. 7. sırada Illinois Üniversitesi, 8. sırada Güney Danimarka Üniversitesi Spor Bilimleri ve Klinik Biyomekanik Bölümü,9. sırada York Üniversitesi Kinesiyoloji ve Sağlık Bilimleri Fakültesi ve 10. sirada Liverpool John Moores Üniversitesi Spor ve Egzersiz Bilimleri Fakültesi olmuştur (https://ceoworld.biz/2019/).

\section{Dünyada Spor Üniversiteleri Yapılanma Örnekleri}

1- Ulusal Tayvan Spor Üniversitesi: Tayvan'daki Spor üniversitesinde 3 yüksekokul ve bu yüksekokullara bağlı bölümler bulunmaktadır. 3 adet sporla ilgili yüksekokul vardır:

Spor Eğitimi Yüksekokulu: Beden Eğitimi Bölümü ve Dans Bölümü mevcuttur.

Sportif performans Yüksekokulu: Sportif Performans Bölümü, Mücadele sporları bölümü ve oyun sporları bölümü mevcuttur

Spor Endüstrisi Yüksekokulu: Rekreasyon Sporları Bölümü, Spor Yönetimi Bölümü, Egzersiz Sağlık Bilimleri Bölümü ile Spor Bilgi ve İletişim Bölümü mevcuttur. Tayvan Ulusal Spor Üniversitesi Lisans Programları: Beden Eğitimi Bölümü, Spor Performansı Bölümü, Top Sporları Bölümü, Spor Yönetimi Bölümü, Spor Bilgi ve İletişim Bölümü, Dans Bölümü, Dövüş Sporları Bölümü, Rekreasyon Bölümü, Egzersiz Sağlık Bilimleri Bölümü

2- Poznan Beden Eğitimi Üniversitesi (Polonya): 3 adet fakültesi vardır: Beden Eğitimi, Spor Ve Rehabilitasyon Fakültesi: Beden Eğitimi bölümü, Spor bölümü, Fizyoterapi bölümü, Nörobiyoloji bölümü, Beslenme bölümü ile Fiziksel kültürde dans bölümleri mevcuttur. 
Turizm ve Rekreasyon Fakültesi: Turizm ve rekreasyon bölümü vardır. Gorziw Wielkopolski'de Fiziksel Kültür Fakültesi: Beden Eğitimi bölümü, Fizyoterapi bölümü, Beslenme/Diyet bölümü ile Turizm ve rekreasyon bölümleri vardır.

3- Wroclaw Beden Ĕ̆itimi Üniversitesi (Polonya): 3 fakültesi vardır: Beden Eğitimi Fakültesi: Beden Eğitimi bölümü, Turizm ve Rekreasyon bölümü mevcuttur

Fizyoterapi fakültesi: Fizyoterapi bölümü, Kozmetoloji (Kozmetik bilimi) ve İş terapisi bölümleri vardır. Spor Bilimi Fakültesi: Spor bölümü vardır.

4-Nippon Spor Üniversitesi (Japonya): 3 fakültesi bulunmaktadır: Spor Bilimi Fakültesi: Beden Eğitimi Bölümü, Sağllk Bilimleri Bölümü, Dövüş Sanatları Bölümü ile Hayat Boyu Spor ve Rekreasyon Bölümü bulunmaktadir.

Spor Kültürü Fakültesi: Budo Eğitimi Bölümü, Uluslararası Toplum Spor Çalışmaları Bölümü, Çocukluk Sporları Eğitimi Okulu, Çocukluk Spor Eğitimi ve Erken Çocukluk Eğitimi bölümü bulunmaktadır.

Tıbbi Bilim Fakültesi: Judo Terapi ve Tıp Bilimleri Bölümü ile Acil Tıp Bilimleri Bölümü bulunmaktadır.

5- Gdansk Beden Ĕ̆itimi ve Spor Üniversitesi (Polonya): Turizm ve Rekreasyon fakültesi, Beden Eğitimi fakültesi, Sporda Yönetim fakültesi ve Yabancı Diller Birimi mevcuttur.

6- Varşova Jozef Pilsudski Beden Eğitimi Üniversitesi (Polonya): Rehabilitasyon Fakültesi, Beden Eğitimi Fakültesi ile Turizm ve Rekreasyon fakültesi mevcuttur.

7- Norwegian School of Sport Sciences (Norveç): Norveç Spor Bilimleri Okulu spor bilimleri alanında ulusal bir araştırma ve eğitim sorumluluğu olan bilimsel bir üniversitedir. Lisans, yüksek lisans ve doktora programları bulunmaktadır. Bölümleri: Fiziksel aktivite ve sağlık, Spor Yönetimi, 
Beden eğitimi, Antrenörlük, Spor, birey ve toplum, Spor biyolojisi ve Açıkhava rekreasyonu / doğa

8-Pekin Spor Üniversitesi (Çin): Spor dalları adları Yüksekokul ve bölüm olarak yer almıştır. Lisans Programları: Beden Eğitimi, Kitle Sporları, Spor Bilimi, Spor Gazeteciliği, Spor Koçluğu, Serbest Sporlar, Geleneksel Çin Sporları, Spor Psikolojisi, Spor Performansı, Spor Ekonomisi, Spor Rehabilitasyonu. Yüksek Lisans Programları: Spor Sosyal Bilimler, Beden Eğitimi ve Spor Antrenörlügü, Uygulamalı Psikoloji, Kinesyoloji ve Spor Bilimi, Geleneksel Çin Sporları, Spor Sosyal Bilimler, Beden Eğitimi ve Spor Antrenörlüğü. Doktora Programları: Kinesyoloji ve Spor Bilimi, Geleneksel Çin Sporları.

9- Litvanya Spor Üniversitesi (Litvanya): Lisans (Fakülte Derecesi) Bölümleri: Spor Koçluğu, Uyarlanmış Fiziksel Aktivite, Spor Eğitimi, Fiziksel Aktivite ve Halk Sağlı̆̆ı, Beden Eğitimi, Fizyoterapi, Spor Fizyolojisi ve Genetiği, Turizm ve Spor Yönetimi, Spor Performans Analizi ve Basketbol Koçluğu Ve yönetim. Fizyoterapi. Spor koçluğu, Spor Yönetimi (yürütme planlanmaktadır). Yüksek lisans: Turizm ve Spor Yönetimi, Uluslararası Basketbol Koçluğu ve Yönetimi, Fiziksel aktivite ve halk sağlığı, Sporun Performans Analizinde Uluslararası planlama, Fizyoterapi, Spor Fizyolojisi ve Genetiği. Doktora Çalışmaları: Biyoloji, Fizyoloji, Beden Eğitimi, Motor Eğitimi, Spor

10-Shanghai spor Üniversitesi (Çin): Çin'deki en iyi spor üniversitelerinden biri bu üniversitede şu anda 15 lisans programı, 6 doktora programı vardır. Aynı zamanda Spor Etkinliği Yönetimi ve Spor Gazeteciliği programlarının ana merkez Çin'deki tek başbakanı olduğu 11 yüksek lisans programı bulunmaktadır. 8 öğretim Okulu vardır. Bunlar:

Beden Eğitimi ve Antrenörlük Yüksekokulu, Dövüş/mücadele sporları Yüksekokulu.

Spor Gazeteciliği ve Yabancı Çalışmaları Yüksekokulu, Kinesyoloji Yüksekokulu.

Ekonomi ve Yönetim Yüksekokulu, Spor serbest zaman, Rekreasyon ve Sanat Yüksekokulu, Uluslararası Kültürel Değişim Yüksekokulu ve Çin Masa Tenisi Kolejidir. 
11-İsveç Spor ve Sağlik Bilimleri üniversitesi (İsveç): Lisans ve yüksek lisans programları bulunmaktadır. Spor ve sağlık programı, Spor bilimi ve sağlık bilimleri programı, Spor bilimi ve koçluk programı ve Spor yönetimi programı olarak hizmet vermektedir. Lisans Programları: Spor ve sağlık programı (didaktik konusunda uzmanlaşma) Spor bilimi ve sağlığı programı Spor bilimi ve antrenörlük programı Spor yönetimi programıdır. Yüksek lisans Programları: Spor Bilimi (genel) Spor fizyolojisi ve biyomekanik üzerine spor bilimi programlarıdır. Doktora Programı: Bir adettir. Zorunlu dersler: Spor Bilimi I (7,5 kredi) Spor bilimi II, spor bilimlerinde güncel araştırma, ulusal ve uluslararası (7,5 kredi) Spor bilimi dersi, doktora uzmanlık alan dersi (15 kredi).

12-Deakın Üniversitesi (Avustralya): Çok sayıda lisans ve lisansüstü sporla ilgili program bulunmaktadır. Lisan Programları olarak; İşletme, Spor Yönetimi, Egzersiz ve Spor Bilimleri, Beslenme, Gıda bilimi, sağlık bilimleri gibi alanları kapsamaktadır. Lisansüstü olarakta insan sağlığı, Beslenme, egzersiz, spor ve halk sağlığı alanlarında bulunmaktadır.

13-Loughborough Üniversitesi (İngiltere): Üniversite bünyesinde spor fakültesi ve Spor teknoloji enstitüsü bulunmaktadır. 2017 ve 2018'e göre sporla ilgili QS Dünya Üniversite Sıralamasında birinci sırada yer aldı. Dünya Üniversitelerinin Akademik Sıralaması (ARWU) tarafından Avrupa'da Spor Bilimleri için 1. sırada. (Dünya Üniversitelerinin Akademik S1ralamasında (AWRU) 2. sırada, dünya çapında 361 kurumun son listesinden spor bilim okullarının ve bölümlerinin küresel sıralaması). Mezunlarının\% 92'sinden fazlası mezun olduktan sonraki altı ay içinde istihdam edildi ve / veya daha fazla çalışma yapılmıştır.

\section{4- Alman Spor Üniversitesi/ Köln (Almanya): 1947'de kurulan Alman} Spor Üniversitesi Almanya'nın Köln kentinde bir spor üniversitesidir. Yaklaşık 6.000 öğrencisi ile Avrupa'nın en büyük spor üniversitesidir. Köln'deki "SpoHo" adlı Alman Spor Üniversitesi, nitelikli öğretimi ve en üst düzeyde uluslararası araştırmayı birleştiriyor. Lisans programları: Spor Yönetimi ve İletişim, Önleme ve Terapide Spor ve Sağlık, Spor ve 
Performans, Spor Gazeteciliği ve Beden Eğitimi bölümleri mevcuttur. Lisansüstü eğitim programları: Almanca dili ile eğitim verilenler: Spor ve Hareket Gerontolojisi, Spor Turizmi ve Rekreasyon Yönetimi, Medya ve İletişim Araştırmaları, Egzersiz Bilimi ve Koçluk, Rehabilitasyon, Önleme ve Sağlık Yönetimi, Beden Eğitimi alanlarını kapsar. İngilizce dili ile eğitim verilenler: Spor Yönetimi, Spor ve Tipta İnsan Teknolojisi, Uluslararası Spor Geliştirme ve Politika, Spor ve Egzersizde Psikoloji alanlarını kapsar. Dünya örnekleri incelendiğinde direk alanla ilgili bölümler ve alan dışı bölümler şeklinde bir sınıflama yapabiliriz. Alan dışı olarak tanımladığımız bölümler Türkiye'deki Yükseköğretim Kurumlarında Beden Eğitim ve Spor Fakülte/Yüksekokulları dışında farklı Fakülte ve Yüksekokullarda öğretilen bölümlerdir. Örneğin, İktisat, İşletme ve Kamu Yönetimi, İktisadi ve İdari Bilimler Fakültesi'nde, Psikoloji, Fen-Edebiyat Fakültesi'nde, Hemşirelik ve Diyetisyenlik, Sağlık Yüksekokulu'nda ve son olarak Gazetecilik, İletişim Fakültesinde verilmektedir. Lisans Programları: Spor Yönetimi ve İletişim, Önleme ve Terapide Spor ve Sağlık, Spor ve Performans, Spor, Macera ve Etkileyici Hareket, Spor gazeteciliği ve Beden Eğitimidir .Yüksek lisans Programları: Spor ve Hareket Gerontolojisi, Spor Turizm ve Rekreasyon Yönetimi, Spor, Medya ve İletişim Araştırmaları, Spor Yönetimi, Egzersiz Bilimi Ve Antrenörlük, Spor ve Tıpta İnsan Teknolojisi, Rehabilitasyon, Korunma Ve Sağlık Yönetimi, Spor ve Egzersizde Psikoloji, Uluslararası Spor Gelişimi ve Siyaseti ve Beden Eğitimidir. Doktora Programı: Egzersiz Bilimi, Doğa Bilimi ve Sosyal Bilimini kapsamaktadir.

\section{Tablo 9. Spor alanı ve sporla ilgili bölümler}

\begin{tabular}{ll}
\hline Spor Yönetimi ve İletişim & Judo Terapisi \\
Önleme ve Terapide Spor ve Sağlık & Çocukların Spor Eğitimi \\
Spor ve Performans & Uluslararası Toplum ve Spor Çalışmaları \\
Spor, Macera ve Etkileyici Hareket & Rekreasyon ve sporla tedavi turizmi \\
Spor Gazeteciliği & Sosyal Spor \\
Spor ve sağlık programı (didaktik konusunda & Spor Rehabilitasyonu ve Sağlığı \\
uzmanlaşma) & Geleneksel Çin Sporları \\
Dans & Performans (Dövüş Sanatları Performans \\
Spor Performansı & Odaklı) \\
\hline
\end{tabular}




\begin{tabular}{ll}
\hline Dövüş Sporu & Dinlenme sporları \\
Topla oyun Sporu & Boş zaman/rekreasyon sporları \\
Spor İşletmeciliği & Sağlık sapmaları olan insanlar/Engelliler \\
Egzersiz ve Sağlık Bilimleri & için beden eğitimi \\
Fiziksel kültür dansı & \\
Askeri Hizmetlerde Beden Eğitimi & \\
\hline
\end{tabular}

Tablo 10. Spor alanı dışı veya alan dışı bölümler

\begin{tabular}{ll}
\hline Fizyoterapi & Yöneticilik \\
Diyetisyenlik & Otel hizmetleri organizasyonu Uygulamalı bilişim \\
Nörobiyoloji & Koreografi \\
Turizm ve Rekreasyon & Kamu Yönetimi \\
Hemşirelik İş Terapisi & Kinezyoloji \\
Kozmetoloji & Uygulamalı Psikoloji \\
Acil Tıp Bilimi & Gazetecilik \\
Erken Çocukluk Eğitimi & İngilizce \\
Psikoloji & Pazarlama \\
Reklam ve Halkla İlişkiler & Bilgi Sistemi ve Bilgi Yönetimi \\
Gençlerle Çalışma Örgütü Organizasyonu & Tiyatro gösterileri ve festivaller düzenlemek İktisat \\
\hline
\end{tabular}

15- Ulusal Spor Üniversitesi (Manipur/Hindistan): Üniversite şu anda Imphal'deki Human Lampak Spor Kompleksi'ndeki geçici kampüsünde faaliyet gösteriyor. Hindistan Başbakanı Shri Narendra Modi, 16 Mart 2018'de Üniversitenin önerilen 325 dönüm alan kurulacak kampüsünün yerini belirlemiştir. Ulusal Spor Üniversitesi, spor bilimleri, spor hekimliği ve müttefik alanlardaki gelişmeler ve gelişmelere uygun olarak yeni fakülteler-okullar / bölümler açma esnekliğine sahip olacaktır. Bir zamanlar geliştiği Üniversite, spor bilimleri, spor teknolojisi, spor yönetimi ve spor koçluğu alanlarında spor eğitimini teşvik eden türünün ilk örneği olacak. Aynı zamanda, uluslararası üniversiteler ile Mutabakat anlaşması imzalayarak en iyi uluslararası uygulamaları benimseyerek seçilen spor disiplinleri için ulusal eğitim merkezi olarak işlev görecektir. Gençlik ve Spor Bakanlığı, Nisan 2017'de Canberra ve Victoria Üniversiteleri ile Mutabakat anlaşması imzalamıştır. Üniversitenin dört fakültesi planlanmıştır. Bunlar;

Spor Bilimleri ve Spor Hekimliği Fakültesi/Yüksekokulu Spor Yönetimi ve Teknolojisi Fakültesi/Yüksekokulu Spor Eğitimi Fakültesi/Yüksekokulu Disiplinler arası Çalışmalar Fakültesi/Yüksekokulu 
16- Güney Afrika Spor Üniversitesi (Güney Afrika): 199O'lı yllarda kurulmuştur. 2018 yılında yapılan değişiklikle Güney Afrika Yüksek Eğitim Kurumlarının spor birlikteliğini sağlama ve sporu geliştirme görevini üstlenmiştir. Güney Afrika Üniversite Spor Konseyi tarafından tanınan Ulusal Üniversite Spor Birlikleri, kendi sporlarının planlanması, organizasyonu, yönetimi ve tanıtımından sorumludur. Son yıllarda Güney Afrika'nın bazı spor dallarındaki başarısının altında mutlaka bu organizasyonun etkisi vardır.

\section{Türkiye'de spor alanına özgü üniversite kurulmasını gerekli kılan ne- denler:}

Dünyadaki Spor Üniversitelerini Türkiye'de bulunan üniversitelerinin Beden Eğitimi / Spor Fakülteleri veya Yüksekokulları ile kıyasladığımızda alanlarımızın çok dar olduğunu söyleyebiliriz. Uluslararası yapılanmalara bakıldığı zaman spor ve hareketin çok farklı spor bilimleri disiplini içerisinde ele alınmakta olduğu görülmektedir. Bunlardan Spor Biyomekaniği, Egzersiz Fizyolojisi, Spor Yönetimi, Spor Tarihi, Spor Sosyolojisi, Antrenman Bilimi, Beden Eğitimi, Rekreasyon, Olimpizm ve Felsefe ve Fiziksel Aktivite gibi bilim alanları kendi uluslararası kongrelerini dikkate değer katılımcı sayısıyla düzenler hale gelmiştir. Türkiye'de de Antrenman Bilimi, Egzersiz Fizyolojisi, Fiziksel Aktivite, Spor Bilimleri, Beden Eğitimi, Olimpizm ve Felsefe, Doğa Sporları gibi yüksek katılımlı özel alan sempozyum ve kongreleri yapılır hale gelmiştir. Dünyadaki spor üniversitelerinin lisans düzeyindeki bölümleri çok çeşitli, çok yönlü, disiplinler arası ve disiplinler içir olduğunu ifade edebiliriz. Son yıllarda sporun fonksiyon alanlarında görülen değişme ve genişleme: Beden eğitimi ve spor alanları değişik içerik ve organizasyon yapıları, farklı karakteristikleri olan geniş bir alana yayılmıştır. Bunlar; spor kavramının kapsam alanı, çocuk ve gençlik sporu, ileri yaşlarda spor, kadın sporu, özel gruplar ve durumlular için spor, profesyonel ve amatör spor, okul sporu, üniversite sporu, yaygın spor, herkes için spor, hayat boyu spor, kulüp sporu, 
iş yeri sporu, serbest zaman ve sağlık için spor olarak sayılabilir. Beden eğitimi ve sporun toplum hayatında kazandığı yeni boyut ve fonksiyonlar, spesifik alanların ihtiyacını karşılayabilecek uzman spor elemanlarının yetiştirilmesini zorunlu hale getirmektedir. Beden eğitimi ve spor alanında eğitim veren yükseköğretim kurumlarından beden eğitimi ve spor öğretmeni, antrenör ve spor yöneticisi yetiştirmeleri yanında toplumun spordan beklenti boyutlarının genişlemesi nedeniyle serbest zamanların değerlendirilmesi, basın-yayın, sağlık gibi sahalarda ortaya çıkan yeni meslek alanlarındaki talepleri de karşılamaları beklenmektedir. Disiplinler arası bir yaklaşım: Spor bilimleri eğitiminin, dünyanın gelişmiş ileri ülkelerinde multidispliner bir anlayış ile verildiği; doğal ve sosyal bilimler yoluyla spor, egzersiz ve sağlığın incelenmesi ve geliştirilmesi için sağlık, fen ve mühendislik gibi doğa bilim alanlarının ve alan uzmanlarının sosyal bilimler alanı ile birlikte spor bilimleri eğitimi içerisine entegre edildiği görülmüştür. Eğitim alanları ve mesleki uygulamaların Türkiye'de olduğu gibi kesin sınırlar ile ayrılmadığı, olaya interdisipliner bir bakış açısı ile yaklaşıldığı, spor bilimlerinin kendisine en yakın olduğu sağlık bilimleri alanı ile iç içe geçmiş olduğu, hatta pek çok ülkede spor bilimleri alanında eğitim veren kurumların adında "sağlik" ibaresinin yer aldığı görülmektedir. Türkiye'de Beden Eğitimi ve Spor Fakülte/Yüksekokulları Beden Eğitimi Öğretmenliği, Antrenörlük, Spor Yöneticiliği gibi dört veya beş bölümden öte gidemeyip dar bir çatının altında sıkışıp kaldığı açıkça görülmektedir. Üniversiteleşme ile Sporun fonksiyon alanlarında görülen değişme ve genişlemeye daha fazla imkan tanıması sağlanabilir (İmamoğlu,2018).

\section{Üniversitelerin Olimpiyat veya üst düzey Şampiyonalardaki katkıları:}

Sporda başarının göstergesi olarak Rio 2016 Olimpiyatlarında alınan madalya sayısına göre yapılan sıralamaya bakıldığında, olimpiyat sıralama- 
sındaki ilk 10 ülkenin içerisindeki ABD, İngiltere ve Avustralya'nın toplam 6 üniversitesinin en iyi ilk 10 üniversite içerisinde yer aldığı görülmektedir. Olimpiyatlarda başarılı olan ülkeler sporla ilgili üniversite sıralamasında üniversiteleri bulunan ülkelerdir. Tabloya göre Türkiye'nin 2017, 2018 ve 2019 yılları içinde bilimsel anlamda dereceye giren üniversiteleri bulunmamaktadır (Tablo 10). Hatta ilk 100 içerisinde bile üniversitesin yoktur. Olimpiyatlarda başarılı olan bir ülke Rusya ve Küba Üniversiteleri sporla ilgili üniversite sıralamalarında puanlama kriterlerine göre ilk 50 içerisinde yer almamıştır. Bu durum bu ülkelerin rejimlerine de bağlı olabilir.

Tablo 11. 2016 Rio olimpiyat oyunlarnda madalya durumlan ve 2017-2019 yıllarn stralamasında sporla ilgili ilk 50 üniversite sıralamasındaki Üniversite sayıları

\begin{tabular}{|c|c|c|c|c|c|c|c|}
\hline Sira & Ülke & Altın & Gümüş & Bronz & 2017 & 2018 & 2019 \\
\hline 1 & $\mathrm{ABD}$ & 46 & 37 & 38 & 14 & 13 & 14 \\
\hline 2 & İngiltere & 27 & 23 & 17 & 7 & 7 & 8 \\
\hline 3 & Çin & 26 & 18 & 26 & - & 4 & 4 \\
\hline 5 & Almanya & 17 & 10 & 15 & - & 3 & 5 \\
\hline 6 & Japonya & 12 & 8 & 21 & 3 & 4 & 4 \\
\hline 8 & Güney Kore & 9 & 3 & 9 & 2 & 5 & 3 \\
\hline 9 & İtalya & 8 & 12 & 8 & - & 1 & 2 \\
\hline 10 & Avustralya & 8 & 11 & 10 & 4 & 3 & - \\
\hline 11 & Hollanda & 8 & 7 & 4 & 2 & 1 & 2 \\
\hline 13 & Brezilya & 7 & 6 & 6 & 2 & 1 & 1 \\
\hline 14 & İspanya & 7 & 4 & 6 & - & 1 & 1 \\
\hline 19 & Yeni Zelanda & 4 & 9 & 5 & 1 & 2 & - \\
\hline 20 & Kanada & 4 & 3 & 15 & 7 & 2 & 2 \\
\hline 24 & İsviçre & 3 & 2 & 2 & - & 2 & 2 \\
\hline 28 & Danimarka & 2 & 6 & 7 & 1 & 1 & - \\
\hline 29 & İsveç & 2 & 6 & 3 & - & 1 & 1 \\
\hline 35 & Belçika & 2 & 2 & 2 & 1 & - & 1 \\
\hline 36 & Tayland & 2 & 2 & 2 & 1 & 2 & 1 \\
\hline 37 & Singapur & 1 & - & - & 1 & 2 & 2 \\
\hline 38 & Hong Kong & - & - & - & 2 & 2 & 2 \\
\hline 39 & Portekiz & - & - & 1 & 1 & - & - \\
\hline 40 & Malezya & - & 4 & 1 & - & 1 & - \\
\hline 41 & Türkiye & 1 & 3 & 4 & - & - & - \\
\hline
\end{tabular}




\section{Ülkelere Göre Dünya Spor İndeksi:}

Global Sports Nations Indeks ve Türkiye'nin Pozisyonu: Nisan 2017 tarihinde Sportcal Global Komisyonu Ltd. tarafından yayınlanan Global spor İndeksine göre Türkiye Dünya ülkeleri arasında tüm spor olaylarında Puanlama sistemine göre 25.nci sırada yer almıştır (İmamoğlu,2018). 2018 s1ralamasında ise Global spor İndeksine (GSI) göre Türkiye 28. Sırada yer almıştır 2019 yılı sıralamasında ise 40. Sıraya gerilemiştir (https://www.sportcal.com). 2019 yılı puanlamam için 83 spor dalında 150 kategoride 641 şehirde yapılan 730 faaliyet incelenmiştir. Dereceleme 90 ülkeyi kapsamaktadır. Çin, Sportcal'in Dünya uluslararası spor Devletlere göre Indeks'in zirvesine 2013'ten bu yana ilk kez ABD'nin üç yıllık saltanatını sona erdirmiştir. Dünya uluslararası spor Şehirler Endeksi'ne gelince, 2018 yılında Tokyo (Japonya) birincilik unvanını aldı. GSI Raporu 2019'da 2018'den toplam 84 etkinlik değerlendirildi. GSI Projesi dört kategoriye göre hesaplanıyor: Ekonomik ve Turizm, Medya ve Sponsorluk, Sosyal ve Sürdürülebilirlik ile Spor. GSI Milletler ve Şehirler Endeksi daha sonra bir ülkenin / şehrin ev sahipliği yaptığı veya gelecekte ev sahipliği yapacağı tüm etkinliklerin GSI Puanları toplanarak hesaplanmaktadır. Her zamankinden daha fazla veri analiz edildiğinde, endeksler 14 yıllık bir süreyi kapsıyor. Geçmişte yedi yıl ve gelecekte yedi yıllık süre. Örneğin, Nisan 2019'da, analiz edilen dönem 2013-2026 idi. 14 yıllık bir dönem boyunca neredeyse 700 büyük çok sporlu oyun ve dünya şampiyonluğunun derinlemesine bir analizine dayanmaktadır. Bu süre, asgari üç Olimpiyat döngüsünden olayların dikkate alınmasına izin verir. Endeks, yaz ve kış olimpiyatları ve olimpiyatlarda 'tanınan' sporlar da dahil olmak üzere 80'den fazla spor içeriyor. Amaç, hangi şehirlerin ve ulusların küresel spor etkinliklerine ev sahipliği yapma hakkı verdiğini ve kazanma hakkını tespit etmektir. Gerçekten küresel olması için endeksin, çok sporlu oyunlar için birkaç istisna dışında, herhangi bir ülkenin teklif edebileceği olaylara odaklanması gerekiyor (https://www.sportcal.com). 
Ülkeler sıralamasına göre 2018 yılı için 90 ülke arasında ilk sırayı Cin, ikinci sırayı Amerika, üçüncü sırayı Rusya, 4. Sırayı Kanada, beşinci Almanya, 6.İtalya, 7. İspanya ve 8. Kore'nin olduğu sıralamada Türkiye 40. Sırada yer bulabilmiştir (Tablo 12). Bu indekse göre sıralamadaki ülkeler küresel spor alanındaki etkilerini performans sporlarına yansıtarak özellikle Olimpiyatlarda altın madalya sayıları ile ülkelerine dönmektedirler. 2017 indeks bilgilerinden yola çıkarak sıralamadaki ülkelerin 2016 Rio olimpiyatları Altın madalya sıralamasına bakıldığında ülkelerin spordaki etkili gücü madalyalara yansımıştır. Bu verilere göre Türkiye 2016 Rio'da en az 3 tane Altı madalya alması gerekiyordu. Türkiye Etki sıralamasında 25.nci sirada bulunurken madalya siralamasında 40.nci sirada yer almaktadır. Türkiye spordaki ülke etki gücünü de Rio'da altın madalya almada etkili olarak kullanamamıştır. 25. Sırada iken bir altın madalya alabilen Türkiye 2017 de 28. sıraya ve 2018 de 40. sıraya inmişken acaba altın madalya sayısını artırabilir mi? Belki de olimpiyatlara kadar daha da aşağı düşecektir. Bunun nedenleri yetkililerce araştırılmalıdır.

Tablo 13. Ülkeler sıralamasında ilk 20 Ülke ve Türkiye

\begin{tabular}{llll}
\hline Siralama & Faaliyetler & Ülke adi & Puan \\
\hline 1 & 43 & Cin & 40.709 \\
\hline 2 & 49 & ABD & 40.619 \\
\hline 3 & 29 & Japonya & 39.631 \\
\hline 4 & 30 & Birleşik Krallık/İngiltere & 32.770 \\
\hline 5 & 32 & Rusya & 32.378 \\
\hline 6 & Kanada & 29.925 \\
\hline 7 & 42 & Fransa & 28.196 \\
\hline 8 & 28 & Almanya & 27.846 \\
\hline 9 & 37 & İtalya & 22.858 \\
\hline 10 & 29 & İspanya & 19.192 \\
\hline 11 & Güney Kore & 18.827 \\
\hline 12 & 19 & Danimarka & 18.486 \\
\hline 13 & 19 & İsviçre & 18.274 \\
\hline 14 & 21 & Hollanda & 18.206 \\
\hline 15 & 17 & Avusturya & 17.533 \\
\hline 16 & 25 & Brezilya & 17.182 \\
\hline 17 & 18 & Katar & 16.227 \\
\hline 18 & 9 & Macaristan & 16.192 \\
\hline 19 & 10 & Avustralya & 14.798 \\
\hline 20 & 18 & İsveç & 14.684 \\
\hline $\mathbf{4 0}$ & 13 & Türkiye & 3.913 \\
\hline
\end{tabular}


Tablo 14. 2018 yılı Şehirler indeksine göre ilk 20 şehir ve Türkiye şehirleri

\begin{tabular}{|c|c|c|c|}
\hline Siralama & Faaliyet sayısı & Şehir & Puan \\
\hline 1 & 13 & Tokyo & 19.867 \\
\hline 2 & 15 & Paris & 16.048 \\
\hline 3 & 16 & Budapest & 14.961 \\
\hline 4 & 8 & Rio de Janeiro & 13.801 \\
\hline 5 & 10 & Doha & 13.679 \\
\hline 6 & 12 & London & 10.747 \\
\hline 7 & 11 & Moscow & 10.241 \\
\hline 8 & 7 & Beijing & 8.388 \\
\hline 9 & 9 & Copenhagen & 8.027 \\
\hline 10 & 5 & Minsk & 6.821 \\
\hline 11 & 6 & Nanjing & 6.615 \\
\hline 12 & 6 & Kazan & 5.866 \\
\hline 13 & 7 & Sochi & 5.857 \\
\hline 14 & 5 & Glasgow & 5.769 \\
\hline 15 & 8 & Abu Dhabi & 5.627 \\
\hline 16 & 6 & Baku & 5.429 \\
\hline 17 & 5 & Lima & 5.217 \\
\hline 18 & 3 & Pyeongchang & 5.213 \\
\hline 19 & 6 & Helsinki & 5.181 \\
\hline 20 & 6 & Innsbruck & 4.808 \\
\hline 227 & 3 & Ankara & \\
\hline 318 & 1 & İstanbul & \\
\hline 335 & 2 & Antalya & \\
\hline 343 & 1 & Mersin & \\
\hline 373 & 1 & İzmir & \\
\hline 397 & 1 & Sakarya & \\
\hline 555 & 1 & Adana & \\
\hline
\end{tabular}

Şehirler indeksinde Türkiye 227. Sırada Ankara, 318. Sıradan İstanbul, 343 sirada Mersin,397 sırada Sakarya ve 555. Sirada Adana ile yer almaktadir.

Faaliyet indeksine göre Türkiye'nin 2018 yılında faaliyeti bulunmamaktadır. 2018 yılında Türkiye'nin şehirlerinin sıralamadaki yeri ve büyük çaplı puan getirici organizasyonlar düzenlenmemesi olimpiyatlarda madalya şansını düşüreceği gibi olimpiyat oyunları düzenleme isteğini hayallerde yaşatabilir.

Maddi destek sağlama: Sıralamada ilk sıradaki üniversiteye bakarsak; Loughborough Universitesi, çok çeşitli spor dallarında birinci sınıf tesisleri bir araya getiren, ülkenin en büyük toplaşımıdır. Kapalı mekan atletizm merkezi ve açık hava stadyumu, spor salonları, 50 metrelik yüzme havuzu, squash, badminton ve netball kortları, kapalı mekan tenis merkezi ve gelişmiş fitness merkezlerine sahiptir. 
Tablo 15. 2018 Yilı faaliyetleri ilk 20 faaliyet sıralaması

\begin{tabular}{|c|c|c|c|c|}
\hline & Müsabakalar & Spor dalı & Şehir & Ülke \\
\hline 1 & FIFA World Cup 2018 & Soccer & Various & Rusya \\
\hline 2 & Olympic Winter Games 2018 & Olympics & Various & Kore \\
\hline 3 & Commonwealth Games 2018 & Games & Gold Coast & Avustralya \\
\hline 4 & Asian Games 2018 & Games & Various & Endonezya \\
\hline 5 & European Championships 2018 & Games & Various & Karışık \\
\hline 6 & IIHF World Championships 2018 & Ice hockey & Various & Danimarka \\
\hline 7 & Paralympic Winter Games 2018 & Paralympics & Various & Kore \\
\hline 8 & Ryder Cup 2018 & Golf & Versailles & Fransa \\
\hline 9 & Youth Olympic Games 2018 & Olympics & Buenos Aires & Arjantin \\
\hline 10 & $\begin{array}{l}\text { FIVB Men's Volleyball World Cham- } \\
\text { pionships } 2018\end{array}$ & Volleyball & Various & Karışık \\
\hline 11 & FEI World Equestrian Games 2018 & Equestrian & Tryon & $\mathrm{ABD}$ \\
\hline 12 & $\begin{array}{l}\text { FIVB Women's Volleyball World } \\
\text { Championships } 2018\end{array}$ & Volleyball & Various & Japonya \\
\hline 13 & Rugby World Cup Sevens 2018 & Rugby sevens & San Francisco & $\mathrm{ABD}$ \\
\hline 14 & $\begin{array}{l}\text { IAAF 17th World Indoor Athletics } \\
\text { Championships } 2018\end{array}$ & Athletics & Birmingham & İngiltere \\
\hline 15 & $\begin{array}{l}\text { FIBA Women's Basketball World Cup } \\
2018\end{array}$ & Basketball & Tenerife & İspanya \\
\hline 16 & $\begin{array}{l}\text { Vitality FIH Women's World Cup } \\
2018\end{array}$ & Field hockey & London & İngiltere \\
\hline 17 & $\begin{array}{l}2018 \text { UCI Road World Champions- } \\
\text { hips }\end{array}$ & Cycling - road & Innsbruck & Avusturya \\
\hline 18 & $\begin{array}{l}\text { IFF Men's World Championships } \\
2018\end{array}$ & Floorball & Prague & $\begin{array}{l}\text { Çek cumhuri- } \\
\text { yeti }\end{array}$ \\
\hline 19 & IFSC World Championships 2018 & Sport climbing & Innsbruck & Avusturya \\
\hline 20 & $\begin{array}{l}2018 \text { UCI Mountain Bike World } \\
\text { Championships }\end{array}$ & $\begin{array}{l}\text { Cycling - mo- } \\
\text { untain bike }\end{array}$ & Lenzerheide & İsviçre \\
\hline
\end{tabular}

Enstitüye ayrıca, atletik ekipman, giysi ve ayakkabı sektöründe inovasyonun sağlanması için İngiltere Spor inovasyon ortağı statüsünün bu organizasyonla birlikte çalışmasına izin verilmiş, koçluk ve geri bildirim teknolojilerinin gelecekteki İngiliz şampiyonlarının potansiyelini en üst düzeye çıkarmak için kullanılması sağlanmıştır. Büyük Britanya'nın Rio 2016 Olimpiyatlarına götürdüğü 382 atletten 28'i Loughborough'da eğitim almıştır ve topladıkları madalyalarla final tablosunda 17. sırayı kazanmışlardır. 2000 yılından bu yana, Loughborough Üniversitesi Spor Teknolojisinde bir derece programına sahiptir. Her yıl yaklaşık 35 öğrenciyi kabul eden Wolfson Makine, Elektrik ve İmalat Mühendisliği Okulu'na bağlı üç yıllık bir programdır. Spor Teknolojisi programı, öğrencilere spor, 
tasarım, teknoloji ve yenilik odaklı geniş bir müfredat sunmayı amaçlamaktadır. Mühendislik içeriğine ek olarak, öğrenciler Spor ve Egzersiz Bilimi, İşletme Okulu, Matematik Bilimleri, Polimer Teknolojisi ve Malzeme Mühendisliği Yüksekokulu'ndaki modülleri inceler. Öğrenciler, kendi güçlü yönlerini ve ilgi alanlarını geliştirebilecekleri çok çeşitli teknik ve aktarılabilir becerilere sahiptir. Üniversite yönetimlerince Geniş maddi desteğin spor alanına yönlendirilmesi için yönetiminde sporla ilgili kişilerce veya işi spor olan kişilerce oluşturulması gerekir.

Üniversiteleşmenin Yönetimsel boyutu: Türkiye'deki mevcut yapılanmada Üniversitelerde sporun temsil edildiği en üst düzeyde Spor fakülteleri olduğu dikkate alınırsa bunların dekanları ve bir profesör temsilcisi olarak senatolarda temsil edilmektedirler. Yönetim kurulunda ise Sadece dekan bulunmaktadır. Bu dekanların bir kısmınınsa spor alanı ile ilgili olmadığı göz önüne alınırsa Türkiye'de spor alanı bu alanda eğitim almış kişilere yönetsel anlamda kapalı gözükmektedir. Kurulacak Spor alanına özel üniversiteler ile her kademede spor eğitimi almış veya sporla iç içe girmiş mesleklerden insanların spor alanına katkısı olacak ve ülkenin spor alanındaki etkisi ve performans artacaktır.

Spor Eğitimi alanında ülke ihtiyaçları ve hedeflerine göre eğitim politikası üretilmesi: Spor alanındaki üniversitelerinin spor enstitüleri spor alanındaki lisansüstü eğitim ve öğretim, araştırma alanındaki dağınıkl1ğını önleyecek ve güçlerin birleştirilerek başarı hedefine yöneltilmesini sağlayacaktır. Spor üniversitesi ülkenin sporunda dünyadaki benzerleri gibi bilimsel ve bürokratik yönlerden yapılandırıcı olacaktır. Spor eğitiminin yaygın olduğu ve performans sporunda başarıya ulaşmış ülkelerde söz konusu eğitimin Üniversite ve Fakülte düzeyinde verildiği de bilinmektedir.

Spor alanına özel üniversite olmasının kazanımları özetle şunlardır:

- Beden eğitimi ve sporda farklı alanların ihtiyacı olan elemanların nitelikli bir şeklide yetiştirilmesi

- Türkiye etkisindeki ülkelere ( Özellikle Türk ülkeleri ve Müslüman ülkeler veya Afrika ülkelerine) spor konusunda bilimsel olarak öncülük etmesi sağlanabilir. Özellikle tarihsel ve dinsel bağlantısı olan ülkelere öncülük etmek gibi bir vizyonunun spor alanında da sağlanması gerekmektedir.

- Lisansüstü eğitimin daha da güçlenmesi 
- Avrupa Birliği Eğitim-öğretim sürecine uyum sağlanması

- Sporun üniversite düzeyinde temsil edilmesi sağlandığında rektör, dekanlar ve öğretim elemanları çalışmaları bütünlük içerisinde olacaktır.

- Sporun fonksiyon alanlarında görülen değişme ve genişlemeye daha fazla imkan tanıması

- Spor alandaki bilimsel araştırmaların arttırılması ve spor bilimlerindeki uluslararası rekabet alanında saygın bir konuma gelinmesi gibi ülkemiz, açısından pek çok yararı olacaktır.

\section{Sonuç ve Öneriler}

Türkiye'de bir veya birkaç Spor Üniversitesinin acilen kurulmasına ihtiyaç olduğu görülmektedir. Türkiye'de Spor Üniversitelerinin kurulmasinın öğrencilere, işverenlere ve topluma çok katkısı olacağı kesindir. Söz konusu üniversite veya üniversitelerin spor tesisleri iklimsel özelliklerde dikkate alınarak kurulmasında fayda vardır. Ankara, İstanbul, İzmir gibi büyük illerde ve Kış sporları için Erzurum, Yaz ve turistik amaçlı sporlar için Antalya ve Mücadele sporları için Karadeniz orta şehri samsunda birer üniversite kurulması Türk sporuna ve nezdinde İslam ülkeleri sporuna ivme kazandıracaktır. 
EXTENDED ABSTRACT

\title{
The Importance of The University in Sports Science's Field
}

\author{
Orhan Ahmet Şener - Osman İmamoğlu \\ Selçuk University - Ondokuz Mayıs University
}

The aim of this study is to explain the importance of establishing universities of sports in Turkey. Literature review was performed. Universities in the world that provide direct education on Sports or Physical Education have been established. Six of these universities were established in China. There are four in Poland and one in Germany, Lithuania, Japan, Russia, Spain, Latvia and Taiwan. It is noteworthy that the universities established in China were established between 1952 and 1958. The dates of establishment of other sports universities vary between 1919 and 1996. There are Sports Institutes, Academies and Universities in different countries around the world that are interested only in sports. There are also independent sports colleges in some countries. In Ukraine there are National Sports Institute and various Sports Faculties. In Australia, there are Sports Colleges and Youth Institutes in Faculties affiliated to Universities. (İmamoğlu, 2018).

In Turkey, there is no university of yet sports. There are sports faculties or sports colleges in different universities. There are also sports related departments related on some health sciences and education faculties. These departments are generally Physical Education and Sports Teacher Departments, Coaching Departments, Sports Management Departments and Recreation Departments. There are sports universities and sports institutes in different countries of the world. In some universities, there are sports-related departments, sports schools (College) or other sports related departments. Sports faculties in Turkey, sports schools and sportsrelated departments linked to other faculties are available. Universities in the United States, United Kingdom, Canada, Australia, Japan, China and Japan have ranked first in the university rankings related to sports. In ad- 
dition, is finding for the years 2018 and 2019 in the ranking of the universities related to sports; top 50 universities in South Korea, Hong Kong, Taiwan, Japan and Singapore. These countries are also successful in terms of winning medals in the field of sports. The states that ranked first in the sports related rankings were also successful in the Olympics. Working with a wide variety of stakeholders and experts worldwide, through its Global Sports Impact (GSI) Project, Sportcal has developed a methodology to measure the holistic impact of events and a standard to capture. Sportcal is a world-leading market intelligence service providing unparalleled news, data, reports and insights into the competitive industry of sports. The countries which are successful according to the Global Sports Impact (GSI) Experts have been found to be successful in sports. Turkey is finding 40nd between the 90 countries for 2018 for Global Sports Impact Experts ranking. In the case of this ranking, the chances of success in the future Olympics are very low.

Here are the achievements of being a private sports university:

- Being in a qualified form of the elements that need different fields in sports education and sport

- Turkey-influenced countries (especially Turkey and Muslim countries or countries of the African countries) may be provided to lead in scientific about sports. A vision such as leading the countries with historical and religious connections in particular should be provided in the field of sports.

- Further strengthening of graduate education.

- Establishment of the European Union education process.

- The rector, deans and lecturers will be in integrity when the sport is represented at the university level.

- The ability of the Sports to change and enlarge the function areas.

- Our country will have many benefits in terms of increasing scientific research in the field of sports and gaining a respectable position in the field of international competition in sports sciences.

It was concluded that one or more of sports University in Turkey that there needs to be urgently established. The establishment of the Sports University in Turkey in Turkey sporting, social, economic and political sense will bring success and reputation. It is useful to establish the universities or universities in question by considering the sports facilities in 
climatic conditions. It need Establishment of Sports University in the major cities such as Ankara, Istanbul and Izmir. In addition, it may be recommended to establish a university for winter sports in Erzurum, Antalya for summer sports and a university in the middle of the Black Sea for Fighting Sports.

\section{Kaynakça / References}

İmamoğlu O. (2018). Spor bilimleri alanına özel üniversiteleşmenin önemi, International 2nd Academic Sports Research Congress, Proceeding Books,pp. 30-42, Batumi, Georgia

https://www.topuniversities.com/university-rankings/university-subjectrankings/2018/sports-related-subjects Erişim Tarihi:2018

https://www.sportcal.com/GSI/GSIExperts Erişim Tarihi:2019 http://tr.eurosport.com/olimpiyat-oyunlari/rio/2016/medal-table-rio2016.shtml. Erişim Tarihi:6/10/2017.

\section{Kaynakça Bilgisi / Citation Information}

Şener, O. A. ve İmamoğlu, O. (2019). Türkiye'de spor alanına özgü üniversitelerin önemi. OPUS-Uluslararası Toplum Araştırmaları Dergisi, 13(19), 1028-1055. DOI: 10.26466/opus.571605 